\title{
REA model, its development and integration as an enterprise ontology framework
}

\author{
Alexey Nikitkov ${ }^{\mathrm{a}, 1}$ \\ ${ }^{a}$ Brock University, Canada
}

\begin{abstract}
Research Question: REA enterprise ontology framework, what is it good for?

Motivation: The historical approach to accounting and management information system design was based on conventions expected by the end-users: debits and credits, accounting cycles, general ledger and journals, bank reconciliations, budgeting function, and select management reports. This approach resulted in gross inefficiencies, data-duplication, and inconsistencies, difficulty with system update, modification, porting, and restoration. An alternative system design theory has been in development since 1982, an approach that is easy to understand, formulate, document, and implement; an approach that applies a basic semantic model of structuring all information flow into a widely applicable enterprise ontology framework that facilitates economic activities and strategic planning for the whole enterprise. Yet, until now, this approach is insufficiently known and seldom utilized.

Idea: Our purpose is to provide a comprehensive theory guide for anyone desiring to be acquainted with the REA.

Data: We review 55 publications comprising dominant Resource-Events-Agents (REA) theory research.

Tools: Methodologically, we obtain, classify, define, and discuss the content of major research streams within REA domain.

Contribution: The paper's contribution is in structured and comprehensive review enabling a novice to REA reader time-efficient acquaintance with the intricacies and benefits of the ontology, and information system researchers with wide-ranging theory review in this domain. We conclude with a discussion of contentions and challenges surrounding REA theory and its future developmental directions.
\end{abstract}

Keywords: accounting information systems, resource, event, agent, REA model, ontology, enterprise, information system, strategy planning, economic activities, multienterprise collaboration.

\footnotetext{
${ }^{1}$ Corresponding author: Alexey Nikitkov, Department of Accounting, Goodman School of Business, Brock University, Email address: anikitkov@brocku.ca
} 


\section{JEL codes: $\mathrm{M} 4, \mathrm{~N} 8, \mathrm{O} 3$}

\section{Introduction}

The historically mainstream approach to information system design was based not only on user information requirements, but user conventions or stereotypes, such as debits and credits, accounting cycles, general ledger and journals, bank reconciliations, budgeting function, and select management reports. This approach resulted in gross inefficiencies, data-duplication, inconsistencies, difficulty with system update, modification, porting, and restoration. At best, structuring systems with such conventions as base objects results in storing the same data at multiple levels of aggregation, which creates inefficiencies in the database. At worst, basing systems on such conventions destroys details that are unnecessary for accounting, but that may facilitate decision making by other enterprise functional areas (Dunn et al., 2016).

In 1982, a seminal model was proposed by William McCarthy (1982) to document accounting information flow, integrating the concepts of resource, events, and agents (REA) and advancing the model of entity relationships from Chen (1976). Since then, the REA developed from a semantic model of depicting accounting data flow to a widely applicable enterprise ontology framework facilitating system design for all economic activities and strategic planning in an enterprise and a domain-independent information system design theory, integrating concepts from computer science, information systems, databases, accounting, economics, and conceptual modeling. The advantage of REA is that it uses a system of simple abstracts R-E-A and data-flows compelling system developers to focus on actual enterprise processes and information needs rather than on conventions.

Despite clear advantages and now nearly forty years legacy, REA has not received sufficient attention from IS academics or practitioners. Today, REA was incorporated into ISO standards for business exchange patterns and served as the basis for at least one cloud-based enterprise system -- Workday, (Dunn et al., 2016) only. Considering the objective benefits that REA offers, we attribute the lack of its use to one cause - insufficient knowledge amongst the relevant group of professionals. The goal of this article is to address this lacuna.

This article is a comprehensive, structured review of REA development, its comparison and integration with other related models, its integration with information systems design, and its enterprise ontology development, as well as discussion of contentions and limitations attributed to it. We endeavor to explain, illustrate, show usefulness and applicability of REA, and by this, create interest for the information system design practitioners and academics. This paper succinctly reviews the progress achieved with REA theory development. Overall, the paper 
summarizes the current state of knowledge of this topic. It creates an understanding of the issue for the reader by discussing all the essential findings presented in the recent research papers, systematically structuring relevant research papers by the area of research development, and by putting them in the appropriate context.

This paper is organized as follows: Section 2 discusses the methodology of literature search and review. Section 3 discusses the REA model development. Section 4 compares REA with other models and describes integration attempts with other models. Sections 5 describes REA integration with AIS. Section 6 deliberates on REA development to an Enterprise Ontology Framework -- historical and current situation, and Section 7 on contentions surrounding REA. Section 8 speaks on REA's future development opportunities and concludes.

\section{Methodology}

A comprehensive review of the extant literature on the subject and a thorough, systematic search was employed based on a list of relevant keywords using the following databases: ABI/INFORM Global, Brock Supersearch, Canadian Business \& Current Affairs Database, EconLit, Google Scholar, and LexisNexis Academic. The initial selection included 89 articles. A subsequent three-stage screening process was employed:

Stage 1, initial screening. Articles that were irrelevant to the research question and topic were excluded based on title and abstract review. Eighty-five papers remained after Stage 1. Stage 2, in-depth review of each article. The abstract, introduction, and conclusion were examined for each paper. Nineteen articles were found to be relevant to the information system design, but not REA modeling/ontology/design theory, and were removed from the review. Sixty-six articles remained after Stage 2. Stage 3, final screening. This stage involved a fulltext read of the paper or selected sections specific to the research question for lengthy papers over fifty pages long that cover multiple topics not relevant to the research question. Eleven articles were found to be teaching cases and were removed from the scope of the study. Fifty-five papers remained after Stage 3. See Table 1 for more information.

\subsection{Major REA research streams}

A remarkable number of studies have been focusing on extending the scope and application of the REA model since 1982. Our search through multiple library catalogs and databases resulted in finding 55 REA-related research articles with several research streams. The first stream is the effort to develop the REA model to an enterprise ontology framework which exemplified by Geerts and McCarthy (Geerts, 2008) to transform REA from accounting to an enterprise model involving 
commitment and policy specifications; White (2008) to apply it in economic activities of a mining company; Church and Smith (2008) to use it in strategic planning of an enterprise; and Geerts and O'Leary (Geerts, 2008) to apply it in a supply chain of physical flow, custody chain and ownership chain.

The second stream is using the REA model to design reusable applications such as semantic web technologies exemplified by Sedbrook and Newmark (2008), a formal specification for the Web Ontology Language (OWL), by Gailly et al. (2008); and teaching accounting information systems by McCarthy (2003).

The third stream is comparing and integrating the REA model with other useful models in accounting and economic activities such as a traditional Debit-CreditAccount (DCA) accounting model (Dunn \& Grabski, 2000); a dominant enterprise resource-planning system called Statutory Accounting Principles model (O'Leary, 2004), and a process accounting model (PAM) to integrate business process management (Sonnenberg \& Brocke, 2014). As Sutton (2010) observes, integration of the REA model into an accounting information system is still ongoing in various applications.

\section{REA model development}

This section attempts to answer several questions: What is the REA model? How was it developed from a generalized accounting model to a design theory as of today? This section covers the research streams of REA, including its conceptual development, its language development, and its application to multiple economic activities (see Table 1).

The purpose of the REA model, proposed in 1982, was to optimize data modeling, recording, storage, and meaningful information extraction and thus consequently adding business value by streamlining information access and sharing in a generalized business environment for both accountants and non-accountants. Optimization was achieved by recognizing a universal structure, a common pattern, representing economic resources, economic events, and economic agents as well as a finite number of relationship types between these economic elements (McCarthy, 1982). Since then, ample developmental changes were made, as we discuss it below, in accord with expanding the modeling objectives, contents, and representation.

An effort made in 1996 was intended to prepare for the combination of all REA tools into one computerized supportive framework (Geerts et al., 1996). A combination of REA modeling concepts with computer-aided system engineering (CASE) tools can help with the creation of a complex information system(s), enabling capturing and storing information about multifaceted economic 
phenomena. Embedding domain-specific program into CASE tools represents a promising way to its software development from algorithmic assistance to support of specific analysis and methodologies like normalization, structured analysis, and Entity-Relationship diagramming.

Since 2004, this research stream is advanced by the work of Geerts and McCarthy (2004), focusing on transforming the REA model from a general accounting model to an enterprise ontology framework of commitment and policy specifications. In this, the ontology concept as a philosophical term has been adopted in enterprise management and system integration. Its philosophical meaning is the beliefs about the nature of reality (Morgan \& Smircich, 1980). In the practical sense, ontology in the enterprise system development is an explicit specification of a shared conceptualization with application in communication support, software development, and system integration (Gruber, 1993; Gruninger \& Lee, 2002).

As a conceptual specification, enterprise ontology depicts the essence of the enterprise operation (Dietz, 2006). A conceptual accounting framework as enterprise domain ontology has been proposed based on the ontological categorizations (Sowa, 1999) to extend the REA framework vertically, in terms of entrepreneurial logic of value chains and workflow; and horizontally, in terms of types and images of commitment in enterprise economic phenomena (Geerts \& MacCarthy, 2004).

A stream of research that is related to REA ontology, and in terms of our previous reference, it "surrounds" REA model, is the development of the eXtensible Markup Language (XML) for operational REA enterprise ontologies (REA-EO) which allows the reuse of scripts between enterprise systems with a feature of preserving enterprise specificities and practices (Geerts, 2004). XML is the technology that allows data recording, processing, and exchanging to support application reuse between enterprise systems. The XML technologies use tag structures to attribute to the explicit representation of semantics and represent a contract to validate enterprise schemas and enable interoperability.

Business rules, policies, and practices are often unique for each business and differ from company to company, and their discovery often presents a challenge. An approach called ontology-driven business rule specification (ODBRS) is proposed to discern and specify business rules for an enterprise model as an extended version of REA-EO (Gailly \& Geerts, 2013). The benefit of the ODBRS is that it presents a methodology of business rule specification in following with the REA pattern, something that can be repetitively applied across business organizations and processes. Its firm reliance on domain-specific knowledge differentiates ODBRS from most of the other approaches. 
The further development of the REA model for enterprise ontology application brought in new elements such as value-added processing, knowledge-based decision support, financial decision support, and accounting knowledge support (Geerts \& MacCarthy, 1999). This paper discusses how to overcome organizational and technological constraints to link multiple systems into one to offer accounting knowledge-based and financial decision-based supports to REA model. One of the prime examples of such integrated systems is Edgar, run by the Securities and Exchange Commission (SEC) of the U. S. Government, offering financial data on publicly traded corporations. A feasibility study was performed to evaluate the use of a financial statement analyzer (FSA) with the Edgar system (Mui and McCarthy, 1987). This study highlights the principal benefit of using REA to implement decision support systems like FSA.

Finally, the research stream looking into REA application to various business information systems, e.g., supply chains, CRM, is ongoing. A paper that focuses on radio frequency identification (RFID) system technology in conjunction with REA (Geerts \& O'Leary, 2014) describes the application of RFID in the supply chain. RFID can be used to provide real-time data to facilitate decision making through monitoring current parameters, such as stock quantity and rate of supply chain movement. The development focused on a highly visible supply chain (HVSC) with its ontology to facilitate visibility and interoperability of partners and locations monitored under RFID. The methods used are ontology primitives as an event, agent, location, equipment, and thing (EAGLET) to define structuring principles, in which the specifications of the EAGLET were adopted from REAEO framework to yield HVSC ontology (Geerts \& McCarthy, 2004). The HVSC ontology allows individual characteristics in supply chains to be traced and captured to address inter-operative issues and communication improvements. In addition, the EAGLET property contains structure rules of Meta patterns, stereotypical patterns, and economic scripts to improve the consistency and accuracy of supply chain specifications (Geerts \& O'Leary, 2014).

As another innovative application, the economic activities of a gold mining enterprise are modeled with the REA framework for its accountability and policy infrastructure (White, 2008). The integration of an intangible information resource and a physical resource requires the extended REA ontology with higher certainty and information quality compulsory in the mining production process. For example, thus generated REA ontology facilitates creating and dynamically modifying the short-range production budget, which is a major planning and controlling activity in mining management. Furthermore, the aggregated REA resource comprises intangible and tangible resource information and applicable to non-mining enterprises in capital budget decision making and other purposes.

The next innovative application of the REA framework is a non-financial management information system for strategic planning based on REA 
architecture of organization economic activity (Church \& Smith, 2008). After the extension of its original framework to value chain and task level configuration, the REA model encompasses a broader range of economic practices and phenomena: management activities to set targets and their performance as well as to learning and growing perspective requirements of the balanced scorecard. It is believed that the application of the REA framework on the strategy systems can be used in other businesses with properties of non-financial integration.

Table 1. REA model development

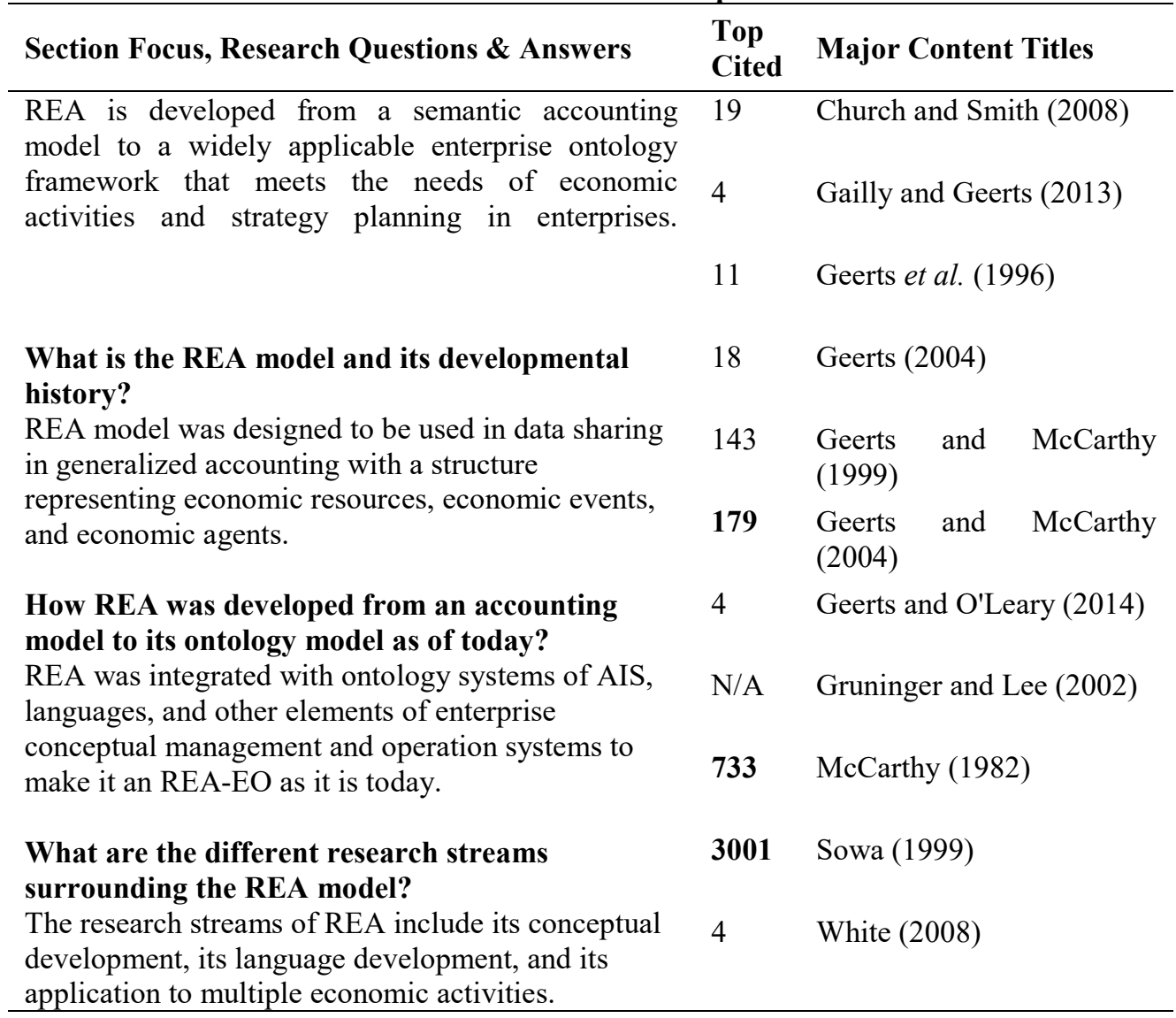

Note: Tables $1-4$ include 55 publications that represent the major topics in the research streams selected in this review, and the top three cited references under each category are highlighted in bold.

\section{Comparison and integration of REA with other models}

How can REA-Enterprise Ontology (EO) integrate with other models? What are the differences between REA-EO and other models currently in use in accounting 
and enterprise ontology? And what are the consequences once REA-EO is integrated with those popular models? These are the questions that this section addresses to illustrate current situations with compatibility and integrate-ability of REA-EO framework in business applications (see Table 2). The integration of the REA-EO framework with other related models is ongoing progress that enhances its applicability and usability.

\subsection{REA-accounting model comparison and integration}

One of the earliest comparisons was conducted by Weber (1986), who compared the initial REA model with 12 wholesale distribution models to examine the similarities, differences, and compliance using the entity-relationship model (ERM) from Chen (1976). ERM was chosen as a measurement standard because of its popularity and relevance to the subsequent REA model. Results show that the initial REA model was a high-level representation of semantics compared to those wholesale distribution models, providing a useful platform in clustering other models. Weber argued that REA design was too general and unclear if it provided adequate representation for non-accounting economic events. Two further developments were recommended: that REA model is developed as domainspecific with lower level of abstraction for non-accounting domains of economic applications, and modification of its ternary relationship to two binary relationships.

As one of the REA accounting concepts, semantic expressiveness means how well a model reflects on underlying reality. Dunn and Grabski (2000) reported that the REA model is significantly more expressive than the debit credit accounting (DCA) model. The advanced semantic expressiveness of REA model has been confirmed experimentally by users evidencing that it results in higher task accuracy due to its qualities of controlling for cognitive fit, field dependence, and accounting knowledge. REA and DCA were also compared in the extension and integration of cognitive fit to accounting models (Dunn, 2001). Cognitive fit is an index used to predict correspondence between task and information formats such as tables and graphs, leading to superior task performance by users. Results show that users prefer REA model because it helps focus on object relationship and enable information finding.

Another report argued that the REA model is not providing ex-ante accounting data for management decisions and not focusing on static accounting (Verdaasdonk, 2003). Accordingly, an object-oriented REA model was presented to enable exante accounting data and to include static structural concepts such as recipes, reservations, and potential contracts as well as behavioral concepts such as incremental costs and opportunity costs. The combinational benefits of structural and behavioral concepts make operational management decisions possible. 
However, this study left unclear if the object-oriented model excluded domains and scenarios of REA model. Future research is expected to highlight the distinction and to integrate the two models.

To further develop the REA-EO model with its static aspect, a dynamic REA (READY) model with its scenario concept has been introduced using the UML sequence diagram to build a REA framework showing interactions between objects (Batra \& Sin, 2008). Several sequence diagram patterns have been enabled, such as fixed assets and payroll. These pattern structures indicate a high level of abstraction, allowing the assembly and specialization of a useful analysis model, which can be extended based on needs in interactions. Also, the READY model contains predictable activities such as search, select, transaction creation, line item addition, transaction review, and commitment, which can be found in different cycles. READY model is confirmed to be a useful and valid extension of REA model in capturing dynamic behavior patterns in accounting scenarios.

While a novel concept, environmental management accounting, currently gains prominence in business; however, traditional accounting models frequently do not provide any support for it. REA-EO framework is instrumental as a basis for environmental management extension because of its rigorous axiomatic features in accounting and auditing (Weigand and Elsas, 2012a). For example, traditional accounting focuses on economic cycles like Receivables, Payables, Payroll, but not cycles needed by socially responsible enterprises like the material flow cycle and product cycle, something that REA-EO can exactly help develop. Moreover, REA-EO not only maps between the two flows to allow correlating of material flow and buffer content but also addresses the organizational capacity to face environmental challenges. Future research is called to focus on carbon emission, water, and human resource management to extend the REA-EO framework for environmental management purposes.

\subsection{Models related to REA-ontology, comparison and integration}

REA design theory was initially described as "too general" for its accounting purpose (Weber, 1986), but also as "pattern - universal," something that speaks about its extensive external applicability and lends much potential to the developments in various fields. Indeed, research reveals that the initial REA model was designed as a generalizable model and as a basis for modeling various business processes to provide data repository and generate abstractions (Denna et al., 1994).

Further, studies have shown that REA design reduces costly errors in conceptual system designs. The necessity to detect, avoid, and correct design errors in conceptual modeling is commonly known. Ideally, such corrections preferred to be done in the earliest stages possible because errors are costly, especially after their implementation into an information system; and design errors may account for 55 to $85 \%$ of total errors (Card \& Glass, 1990). Gerard (2005) tested the 
conceptual modeling of the accounting information system (AIS) and its efficacy on accuracy as a domain-specific pattern encoding knowledge structure in REA model. The results of this study show that the accuracy of conceptual modeling is significantly improved when REA model is used as a structure to organize participant's knowledge. The author argued that it is not reasonable to use any conceptual modeling to detect design errors because models that better communicate structure knowledge, e.g., REA, reduce design errors in domainspecific patterns.

Several studies explored application of REA modeling to auditing, specifically to the auditing of information systems and their risk assessment (Carnaghan, 2006; Weigand \& Elsas, 2012b). Carnaghan (2006) compares several commonly used models for audit risk assessment and states that the key difference with using the REA model is that it does not correspond closely to the "physical reality" of a particular business process but captures economic essence of the transactions and then uses economic or value chain perspective to depict the business process. Consequently, REA model's definition of resources is more precise compared to the relatively broader International Organization for Standardization (ISO) standards, and thus a richer and more informative model can be created using REA.

Further, traditional company-ordered systems auditing is not necessarily based on the company's long-term business interests and may not meet the requirements of a modern organization. Weigand and Elsas (2012b) introduced a REA-EO-based Service-Oriented Auditing (SOAu) framework to show that it fulfills most requirements and fully aligns with fundamental principles for auditing such as those in owner-ordered auditing. SOAu framework is built by integrating REAmodel-based auditing with several traditional auditing techniques where REA bridges the gap between business auditing and IT systems. Such implementation allowed the author to address the concern expressed in Carnaghan (2006) that REA does not provide constructs and descriptions for risks and controls.

Enterprise production planning is an integral part of business operations, and the REA framework has been applied to create a value-oriented model of production planning (Vymětal et al., 2008). This study suggests that REA brings several advantages to enterprise production planning. First, users can customize business processes to support distribution using the interactive modeling environment. Second, REA fits well with information technology tools to act as a process modeling guide for model-driven design. And third, and perhaps most importantly, REA aligns long term business processes, minimizing changes in the information system on the organization-wide scale.

The notions of tracking and tracing are essential in supply chain management. Tracking is the act of following a product path from supplier to customer, and tracing is the identification of the product's origin (Bechini et al., 2008). A conceptual model based on the REA-EO framework provides a foundation for ISO open-EDI transaction standard. It is used in a reference model to support the 
tracking and tracing of products and money flow in economic data registration for both enterprises and supply chains (Laurier \& Poels, 2012a). REA conceptual model can be used to track and trace products through multiple supply chain partners, thus advancing the meaning of "tracking" and" tracing," and becoming an excellent tool for supply chain integration.

Two of the most commonly used technologies in ontology modeling are modeldriven development (MDA) and domain-specific modeling (DSM). Meliš et al. (2013) investigated how they combine with REA. Results show that REA modeling is better supported by DSM, which offers benefits of domain knowledge use, verification, and validation, lower testing requirements as well as a limited amount of modification and changes. However, in the case of frequent changes in semantic abstraction, MDA is recommended due to the limitation with narrow domain and semantic abstraction of DSM.

Table 2. Comparison and integration of REA with other models

\section{Section's Focus, Research Questions \& Answers $\quad \begin{aligned} & \text { Top } \\ & \text { Cited }\end{aligned}$ Major Content Titles}

REA has been compared and integrated with other useful models in accounting and economic activities such as DCA, SAP, READY, and PAM models to expand the usability and applicability of REA model.

Can REA-EO integrate with other models?

Yes, and the integration promotes the application and development of the REA-EO framework, such as the ERM, DCA, and READY models.

What are the differences between REA-EO and other models in an enterprise?

The major differences are that most of the other models 65 focus on a narrow field, but the REA model is more generalized with the potency to become an integrated and wide-cover ontological framework.

\section{What are the consequences once REA-EO}

is integrated with the other models?

The integration of REA with the other models, such as the languages, information systems, and operation and management models, enlarges the application fields and 21 enhances the potential of REA- EO to be developed into a widely acceptable framework in enterprise practice.

$15 \quad$ Batra and Sin (2008)

122 Bechini et al. (2008)

340 Card and Glass (1990)

65 Carnaghan (2006)

14 Denna et al. (1994)

65 Dunn (2001)

44 Dunn and Grabski (2000)

$4 \quad$ Laurier and Poles (2012)

N/A Meliš et al. (2013)

Verdaasdonk (2003)

12 Vymětal et al. (2008)

37 Weber (1986)

$3 \quad$ Weigand and Elsas (2012) 


\section{REA integration with accounting information systems}

While the REA framework offers many benefits for system design, it was rarely integrated with accounting information systems (AIS) or advanced manufacturing systems (AMS) due to differences in data type, volume, and timing. This section describes and categorizes publications addressing the following questions (see Table 3): What AIS components integrate well with the REA model? What role the REA model plays in the AIS integration? And what are the consequences for the integration with AIS or other enterprise systems? Based on the literature, we review two categories: database and non-database AIS integration.

\subsection{Database-related AIS integration}

Today most businesses use accounting databases. The static meta-data view of the accounting database did not meet the requirement of the accounting environment and needed to be changed (Chen \& O'Leary, 1995). REA model as a domainspecific knowledge-based system can be used to guide the database basic schema evolution to support dynamic accounting database in an object-oriented data modeling. Indeed, the REA has been successfully used as a prototype system to demonstrate database identification, development, and functionality (Chen \& O'Leary, 1995).

In an example of databased development, to integrate accounting domain knowledge in view modeling and view integration, an automatic software engineering tool called REACH and a computer-aided software engineering (CASE) tools were used by Rockwell and McCarthy (1999). Several limitations in the implementation were observed, including 1) REA model was used for view modeling but not in full heuristics; 2) implementation focused on accounting transaction cycles only; 3) only a few industry types were used during view integration; 4) method domain is integrated only of structural analysis and semantic database. These limitations were considered and need to be improved in future integration, especially those related to the three domains.

In another database development targeting third-party logistics enterprises, an AIS model was rebuilt by the application of the REA model, a revised E-R database, and an event drive in which E-R database is a data linkage ( $\mathrm{Su}, 2009)$. The advantages of the new AIS are that it assists the maintenance of a close relationship between the third-party logistics enterprises and other businesses in information collection and business coordination; connects users in the interactive interface as in value chain management; and integrates real- time processing, standard cost, approval control, and budget management. 
Furthermore, firm strategy management and decision making can be enhanced by database development through the REA model (Joseph \& George, 2005; Zaharie et al., 2011). A study attempts to get management accountants involved in IT database development to link the design potential of the REA model and the performance framework of the balanced scorecard (Joseph \& George, 2005). Results show that the involvement enables management accountants to establish their partner roles in strategic planning and assists in AIS development with several benefits, such as offering opportunities to partner with senior management in strategy development. Further, Zaharie et al. (2011) generated a dimensional model using REA-EO critical for decision support system based on a data warehouse. The ontology-based dimensional model is subject to adjustment and validation through data sources and user needs. The model favors communication with stakeholders by shifting focus on business processes and policy, and facilitates risk reduction in decision making.

\subsection{Non-database AIS integration}

This category includes AIS integration in accounting concepts, manufacturing systems, communication, and contracting management. Sharing accounting concepts across functional boundaries is called augmented "intensional" reasoning (Geerts \& McCarthy, 2000). Domain-specific knowledge is augmented, including REA primitives, conceptual schema definition, and structure. The benefits of the application of augmented intensional reasoning are that it made the AIS design and implementation less time-consuming and less costly. Another study focuses on the user understanding of conceptual schemas of REA model (Poels et al., 2011). Results show that REA model offers more accurate understanding of business policies and processes through user validation of conceptual schemas and subsequent improvements in engineering requirements. Improved analyst-user communication ensures the detection of invalidity and incompleteness, and thus the success of required task validation.

The integration of an advanced manufacturing system (AMS) with AIS is complex and not attempted until Grabski and Marsh (1994). They show that integration is facilitated by using the REA model to link the AMS to AIS via cost drivers indicating a novel approach to identify manufacturing cost drivers during modeling. The linkage is demonstrated to implement manufacturing data into general accounting acquisition cycle. Leech (1994) reviewed the linkage and argued that it is necessary to limit the modeling to the inside and outside agents of a manufacturing operation and that REA model enables all cost elements and cost drivers in the linkage. Nevertheless, Leech agrees that this is a comprehensive approach with an excellent contribution to data modeling in complex domains such as the integration of AIS and AMS.

One can see AIS research as natural and design science research in which the 
former focuses on understanding phenomena to find new truths, and the latter focuses on creating artifacts (Geerts, 2011). The natural science pattern has been applied to design science called the design science research methodology (DSRM, Peffers et al., 2007) to enable result evaluation. Geerts (2011) integrated DSRM into the operational specification of AIS literature using REA model through retroactive analyses of six AIS publications. Results from the analyses indicate that current research is driven by the needs coming from accounting practice, which is focusing on creating new AIS artifacts through web technology. Future exploration includes in-depth research on integrated use of knowledge tools and specification of AIS artifact using REA framework.

Further, research should focus on improving enterprise AIS by using the REA-EO model to understand data sharing and communication within and between enterprises through the input and output processes (Lupasc et al., 2010). Different ontology models are attempted to improve communication between enterprises to create interoperability and improve reusability and reliability. Compared to other ontology models such as Enterprise Ontology, Business Model Ontology (BMO), e3-Value Ontology, and TOVE, the benefits of REA modeling are the enterprise conceptualization, knowledge reuse, and sharing to identify enterprise actors and exchange values.

Commercial contracting language is a unique area where the application of REA model can support user-defined contracts, automatic execution monitoring, and user-defined state analysis before, during, and after execution (Andersen et al., 2006; Jones et al., 2003). Analyses of actual commercial contracts confirmed that a variety of contracts could be expressed using the contracting language, which in turn will promote their integration, management, and analysis in an operational environment.

Table 3. REA Integration with Accounting Information Systems

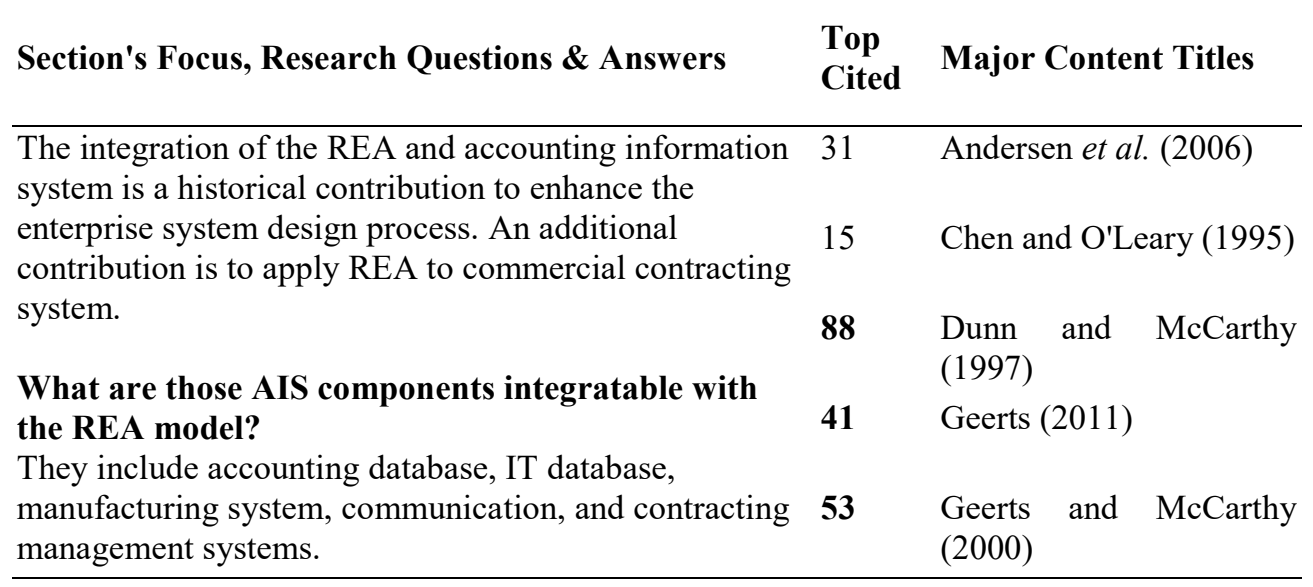


Section's Focus, Research Questions \& Answers $\quad \begin{aligned} & \text { Top } \\ & \text { Cited }\end{aligned}$ Major Content Titles

What are the roles of the REA model playing in the \begin{tabular}{lll}
\hline Grabski and & Marsh
\end{tabular}

AIS integration?

REA model overcomes the differences in data type,

volume, and timing to make possible integration with the

ontology system.

Joseph and George

Lupase et al. (2010)

What are the consequences after the integration of 13

Poels et al. (2011)

AIS and other enterprise systems?

The integration supports the dynamic database systems, 19 enables computerization, and offers data sharing and communication to meet the next generation needs of operation and development of enterprises.

Rockwell and McCarthy (1999)

Zaharie et al. (2011)

\section{REA development to an enterprise ontology framework- historical and current situation}

Enterprise ontology is one of the most discussed topics in REA framework development. This section attempts to answer these questions (see Table 4): Who was the first to introduce the concept of ontology into the REA model? What are the ontology and REA-EO framework? And how was the REA-EO framework developed to meet the needs of enterprises? By answering these questions, this section defines the ontology and REA-EO concepts and classifies the REA-EO research stream as conceptual development, language development, and REA-EO applications.

\subsection{REA-EO conceptual development}

The ontology concept was first suggested by Geerts and McCarthy (2002) and further developed by Geerts and Wang (2007). The individual primitives of the original REA framework have been analyzed collectively as domain ontology, including its economic events and resources, which was relying on classification concepts from Sowa (1999). Following Sowa, the REA ontology was defined as 1) independent building blocks of enterprise information architecture including economic events, agents and resources; 2) relationship between categories such as between internal and external economic agents as salesmen and customers or between external agents as trading partners; 3) extension and integration of the relationship between categories for future REA ontology development. Geerts and Wang (2007) further developed the REA-EO model to meet the requirements of changing business environment, which is built by the combination of a leaner 
enterprise schema to capture domain-specific semantics and ontological specification.

Other conceptual development includes conceptual data modeling (Laurier \& Poels, 2012b) and conceptual semantics building (Batra, 2012). Two ontology derived patterns of REA-EO and unified foundational ontology (UFO) models were used to construct a two-dimensional framework (Laurier \& Poels, 2012b). They suggest that the application scenario extends the conceptual data pattern to both, more general in its application domain and more detailed in transactional data aggregation. Further, Batra (2012) came forward with an argument that REA formulation is incomplete and suggested a new model, called Entity-RelationshipEvent Network (EREN), which extends REA in conceptual semantics. EREN design follows the same cognitive theory as REA and similar diagrammatic notation for use in documentation and unambiguous communication (Veres \& Mansson, 2005). The distinguishing feature of EREN is that it facilitates both descriptive and design roles of data modeling between analysts and users.

Sonnenberg and Brocke (2014) proposed a Process Accounting Model (PAM) to integrate business process management (BPM) and REA accounting model on a conceptual level to evaluate process state changes: process design and run time. PAM works as a lightweight data-structure to facilitate the integration of processaware information system and traditional double-entry bookkeeping AIS to enable process-oriented accounting.

\subsection{REA-EO language development}

This section includes the XML vocabulary (Geerts, 2004), the Unified Modeling Language (UML, Gailly et al. 2008), the Semantic Web Rule Language (SWRL, Sedbrook \& Newmark, 2008), the eXtensible Business Reporting Language (XBRL, Amrhein et al. 2009), and the domain-specific language (DSL, Sedbrook, 2012). The application of XML vocabulary to operational enterprise ontologies (Geerts, 2004) depends on the economic phenomenon definition of the enterprise ontology, which can be extended to capture diverse economic phenomena. The extensions may include economic primitives of custody, linkage, commitment, typification, and enterprise concepts of financial cost and business process.

The UML development is in the attempt to increase the formalization of the REA framework in its enterprise ontological transformation (Gailly et al., 2008). UML is developed by applying the Web Ontology Language (OWL) in REA to define accuracy and develop automation, knowledge representation, software engineering, and interoperability. Another OWL related language is SWRL (Sedbrook \& Newmark, 2008), which is developed to transform metadata, logic and ontology concepts to diagrams to interpret them in machines and web sites, to enable multi- 
enterprise collaborations. A case study confirms that the combined enterprise schema improves the agility and adaptability of partnership operation in vehicle sales environments.

DSL allows REA-EO to express business policies in its application and maintenance of management knowledge on its way to automation (Sedbrook, 2012). They found that communication and cooperation between agile teams and stakeholders require advanced improvement in policy modification through automation to reduce costs (Sedbrook \& Newmark, 2008; O'Leary, 2010). DSL provides the visual interface and specific components in REA-EO to offer business users an effective platform with patterns and database generating tools.

Finally, XBRL is proposed by Amrhein et al. (2009) based on the opinions of Geerts and McCarthy (1997) that a technological language is needed to assist REA to take its advantages of efficient information capturing and better decision making. XBRL enables the capturing of financial and non-financial business information and performance measures within a business and across supply chain to provide efficient, semantic, and interoperable gains to meet the dynamic reporting needs. The combined model helps management to understand and identify opportunities for faster and smarter decision making through tagging and effective sharing economic information.

\subsection{REA-EO applications on enterprise ontology}

REA-EO applications include its formalization, applications on supply chains and value chains, and application on ontological strategy making. As its formalization, a methodology called Ready, Intermingle and Accept (RIA) is designed based on the REA-EO framework using OWL formalization to automate domain changes among wiki topics and support decision making (Sedbrook, 2010). A field study was used to confirm that the created methodology maintains semantic wiki connections and domain knowledge to support a large and complex network of curriculum knowledge. In addition, formalization of REA-EO facilitates the discussion of REA extension as its consistency and interoperability of extended ontology. Ito and Vymetal (2013) argued that a formal description of REA-EO model is lacking and should be established to define REA-EO at its operational level using formal logic tools such as the language of the Tasks-Agents- Products model (LTAP). They suggest that REA ontology might be defined using smaller number of concepts but not over-specified.

Secondly, Systems, Applications and Products (SAP) design has a strong effect on supply chain and value chain business process engineering since SAP is a leading resource planning system and has been adopted by a great number of large firms such as those in Fortune 500. A study was conducted to compare REA model and SAP system in their relationship within the database, semantic and structure 
orientation (O'Leary 2004). Database and structure orientation of SAP are a highly specified systems with implementation-specific compromises based on accounting artifacts, production planning, and human resources. The author argued that limited attention had been paid to the integration of value creation evaluation and supply chain analysis.

Further, since REA-EO has a value-oriented resource perspective, Kašík (2011) suggests that creating product features and exchanging products with other agents, through conversion or exchange processes, this is how an enterprise increases or decreases its total resource value. The study attempts to model the abstraction of REA-EO on four levels as value chain, value system, task, and business levels to introduce a dynamic aspect using an activity diagram of UML. The advantage of this dynamic model is in ensuring consistency with task modeling for the whole REA-EO model.

Huňka et al. (2011) studied the integration of REA ontology into the supply chain. They show how close REA-EO is to the supply chain concept from the semantic architecture point of view and describe how REA-EO gives a detailed description and modeling of a supply chain. A design science approach uses REA-EO framework to integrate supply chain, value chain, and business processes to build a conceptually sound stimulation model (Laurier \& Poels, 2013). They demonstrate that REA allows the creation and integration of distinct models into a complete value system model to address invariant conditions. Also, Bakkenist and Bakkenist (1999) show how the ExSpecT language can be used to provide visualization, statistics, and analysis within the integrated model, which in turn, can be used to build discrete event simulations.

Thirdly, REA-EO was instrumental in the field of enterprise strategy making. Here, it was applied to service (intangibles) ontology (Sicilia \& Mora, 2010), policy level specifications (Geerts \& McCarthy, 2006), and enterprise strategy planning (Church \& Smith, 2008). While most of the REA-EO studies focus on business with sales of tangible goods, its application to the field of intangibles has been rarely reported (Sicilia \& Mora, 2010). One of the reports on service ontology is from Mora et al. (2011), which addresses service specification, service ontology initiatives, and key theoretical elements of service ontology. These studies highlight REA ontology usefulness, noting that provision of services can be recorded at the time of sale or commitment.

Policy level specifications define enterprise guidelines and constraints. Geerts and McCarthy (2006) explore two essential semantic abstractions of typification and grouping extensions for REA primitive, in which typification abstraction links an object to its concept and grouping abstraction aggregates objects into collections. Three types of policies recognized as knowledge-intensive descriptions, target description, and validation rules. 
Furthermore, strategy planning is noted as one of the innovative applications of REA- EO framework in replacing the traditional capital budgeting (Church \& Smith, 2008). Kaplan and Norton (1996) argued that traditional budgeting creates barriers and limits access, and Fabozzi et al. (2008) argued that traditional budgeting may not incorporate uncertainties, risks, and option values sufficiently. Venturing to address these shortcomings, Church and Smith (2008) demonstrated that REA-EO model could be used by the decision-makers to compare alternatives under various conditions, given the relationships of ontology strategies, to predict corresponding performance. For example, a balanced scorecard, implemented as an REA-EO model, may be instrumental in understanding the effects of a project on strategy alteration and benefit reduction.

Table 4. REA Development to an Enterprise Ontology Framework - Historical and Current Situation

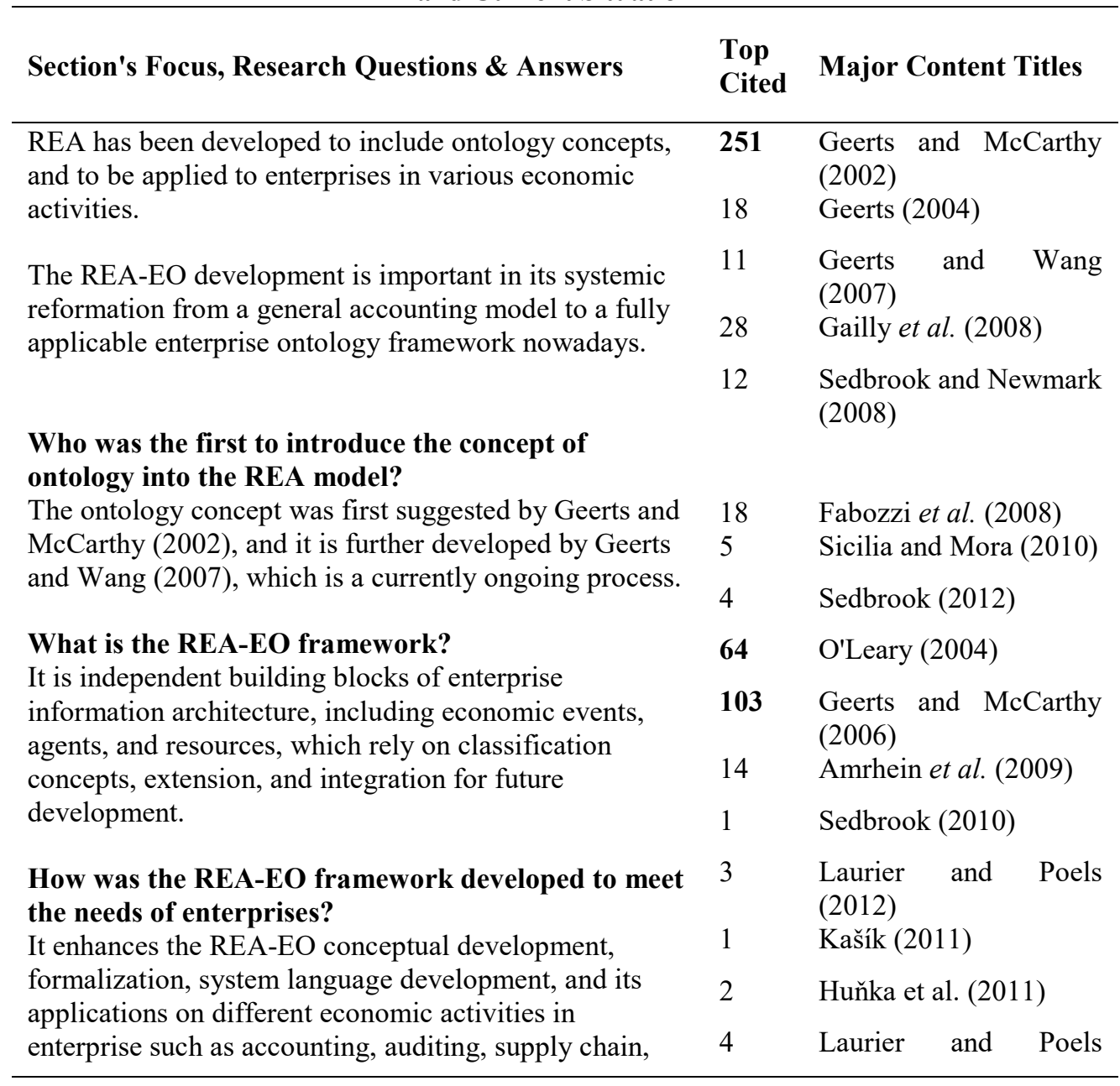




\begin{tabular}{lll} 
Section's Focus, Research Questions \& Answers & $\begin{array}{l}\text { Top } \\
\text { Cited }\end{array}$ & Major Content Titles \\
\hline value chain, as well as strategic planning and execution. & 2 & $\begin{array}{l}(2013) \\
\text { Batra (2012) }\end{array}$ \\
& 20 & $\begin{array}{l}\text { Weigand and Elsas } \\
(2012 \mathrm{~b})\end{array}$ \\
N/A & $\begin{array}{l}\text { Ito and Vymetal (2013) } \\
\text { Sonnenberg and Brocke } \\
(2014)\end{array}$ \\
\hline
\end{tabular}

\section{Contentions surrounding REA}

This section attempts to answer the following questions: What are the main points of contention with REA? How do these disagreements or limitations affect REA's current application and exploration of future developments?

Most of the recent contentions relate to REA ontology development, its language development, and other applications such as supply chain and auditing. These contentions and arguments tend to be a positive critique with the intention to improve and enrich the REA-EO framework. Below we discuss the main points of contention.

As the first contention with REA ontology development, there are viewpoints published online that the REA model is mostly an educational model and does not fit the enterprise's needs and application. One of the goals of this article is to address this misunderstanding by imparting readers with a more comprehensive and informed view of REA. As discussed by McCarthy (2003), one of the application fields of REA model in the past 20 years was education, but Poels (2011) argued that since 2004 the development direction of REA had been changed remarkably towards its enterprise applications (Geerts \& McCarthy, 2004). The promoting factors for the direction change are the involvement of REA in a number of international standardization efforts, e.g., ISO Open-EDI initiative and others promoting the development of REA in enterprise ontology (Laurier \& Poels, 2012a); and the involvement of REA as a theoretical basis for reference models underlying the Enterprise Resource Planning (ERP) system (O'Leary, 2004). Both promoting factors witness the importance of REA model in current and future enterprise ontology development.

Also, one of the common arguments against using REA is that enterprise schemas are not always yielding to the REA pattern, and thus compromises must often ensue due to practical considerations (Rockwell \& McCarthy, 1999). This 
argument is the inducement for REA-EO to be extended in its definition of enterprise concepts, integration of REA-EO specification with advanced upperlevel enterprise ontology, and its language development with standardized common vocabulary (Geerts, 2004).

Furthermore, Church and Smith (2007) argued that one needs to pay attention to the activities relating to intangible assets and the activities in the conversion process to create tangible assets when developing an REA model. The increases of intangible assets such as human, information, and organization capitals often drive business improvements. For instance, investment in human capital can increase employees' competency, lead to undertaking a strategic initiative, or a change in strategic objective can produce an organizational change not captured by the REA model if it focuses only on tangible assets.

The second contention focuses on language integration. Mayrhofer and Huemer (2012) argued that the REA model did not deliver a concept that can be understood by business experts, and thus an easy to understand REA specific language can accelerate and streamline its use in AIS development. As a consequence, a domainspecific modeling language (DSL) called REA-DSL has been developed to deliver an REA notation while maintaining the full expression of the REA-EO model. Furthermore, an entity-relationship diagram (ERD) can be automatically generated from REA-DSL using Microsoft Visual Studio T4 Text Templating Engine, resulting in a promising prototypical mapping.

The third contention focuses on REA limitations when it comes to applications such as supply chain and auditing. A recent significant contribution from the REA model is the supply chain ontology (Grubic \& Fan, 2010). Geerts and O'Leary (2014) contributed to the EAGLET ontology and argued that the compliance of EAGLET is much higher compared to the traditional supply chain ontology. The primitive and structuring rules of the EAGLET ontology are validated against a series of practice-oriented sources such as the Metro Group. Also, Laurier and Poels (2013) argued that supply chain, value chain, and business process models are not standalone artifacts but parts of integrated reality, in which REA-EO can be applied to support simulation of supply chain and allow for incorporation of financial parameters.

With regards to the application to auditing, it is argued that limitations exist in authorization and other policies of REA ontology because they did not derive from principles but as objects, relationships, or commitments (Hruby, 2006; Geerts \& McCarthy, 2006).

Considering the application of REA model to the auditing system, Weigand and Elsas (2012b) suggest that the stated weaknesses are related and can be remedied 
by extending REA along with the principles of the owner-ordered audit system. The extension can be made by the integration of an ownership interface with an ontology information system to enhance the definitions between ownership, accounting, and policies in the REA ontology.

\section{Future REA developments and conclusion}

Unprecedented technological advancements of the last decade created challenges and opportunities for businesses and drastically affected the accounting profession. The holistic design of the REA model makes it a framework of choice to address present challenges. Exploratory and confirmatory research is needed for all applications, and in the areas, we describe below. We formulated our suggestions for future research based on observing the current state of information system development theory and practice and research directions resulting from the literature review.

The ever-increasing amount of structured accounting data, supplemented with huge volumes of unstructured data that companies obtain via social networks, clicksteam, and meta-data, necessitate database designs based not on former business conventions (e.g., GL, budget accounts, double-entry system), but on foundational constructs that closely resemble the underlying reality of business and data-flows, the REA being a prime example.

Today, most large and mid-size business systems rely fully or partially on cloud storage, computing, and Saas. O'Leary (2015) discusses Workday as an example of successful integration between Saas and enterprise systems, where system architecture is based on REA. Additional research is needed to inform on specific benefits of using the REA as the conceptual foundation to underwrite the integration effort or for cloud-based system design.

Fast pace changes in the business environment demand agility on the part of companies. One of the core challenges is changing the underlying information systems to align with and support novel business models and processes. This includes adding the valuable and meaningful system extensions, integrating new application modules, transferring or updating data, and re-training employees. Systems based on the semantics of an enterprise's underlying reality are more agile than the systems founded on artificial constructs (McCarthy et al., 2003), more transparent for re-design change, and more meaningful for the end-users, even during and after the change. Research is needed to illustrate and inform how REAbased systems help achieve higher levels of agility during the periods of the business change.

The accounting profession is undergoing a drastic transformation. A time when the end of the fiscal year was marked by weeks of finalizing the trail balance and 
producing financial statements is a property of the past. The last decade has changed, and the near future will change even more how accounting is done, and the systems accountants use. Accountants post less and less transactions in the AIS; instead, transactions are auto-fed from the web sites or remote systems. The chart of accounts in the GL is increasingly influenced by XBRL and comparability considerations. An on-premises annual audit is becoming obsolete in favor of a remote, full sample, every transaction, concurrent audit, for a system residing at an inaccessible data-center. The scope and emphasis of accounting risks and associated controls are rapidly changing toward IT and system-related risks. REAEO framework offers significant aid during the time of transition and necessitates design-science future research into specific meritorious implementations. For example, first direction of future research is the design language integration with the REA-EO framework, which extends its application to different enterprises with various business models and requirements. The ongoing language integrations are OWL (Sedbrook \& Newmark, 2008; Zaharie et al., 2011), XBRL (Amrhein et al., 2009; Geerts, 2011), and DSL (Sedbrook, 2012). The integration of OWL into the REA-EO framework promises to provide a platform to organize multi-enterprise ontologies to define and mitigate multi-enterprise collaborations (Sedbrook \& Newmark, 2008) and to model application domain at policy and operational levels (Zaharie et al., 2011). On the other hand, integration of XBRL into REA-EO framework will provide internal strategic business reporting to multiple stakeholders (Amrhein et al., 2009) and specify a comprehensive network for AIS artifact purpose (Geerts, 2011). In addition, the DSL integration into REA- EO will support DSL improvement across diverse domain ranges and DSL refinement to facilitate the integration between REA-EO and UML-driven approaches.

The second future direction is model integration related to auditing processes; for example, the integration of an auditing model exemplified by Weigand and Elsas (2012b), the integration of IT control with auditing and XBRL by Geerts et al. (2013), and the integration of PAM model by Sonnenberg and Brocke (2014). Research is needed to explicate the formalization of internal controls derived from REA models.

Furthermore, the three components, IT internal control, the continuous auditing (CA), and XBRL, are expected to promote future REA development (Geerts et al., 2013). Practice suggests a potential for cross-pollination between the IT internal control area and XBRL, but at present, there is a lack of theoretical justification; experimentation and evaluation are expected for the CA and REA artifacts. The cross-discipline approach, the use of multiple and overlapping research paradigms, is often the way of advancement and solving problems in a complex accounting world.

As mentioned in Section 5, BPM and REA accounting model is integrated to build PAM to evaluate process changes (Sonnenberg \& Brocke, 2014). In its future 
research, PAM may be used for model extensions, e.g., to enable economic interdependence among process designers, accountants, and auditors, where relevant accounting data could be used for process validation at the design time. Furthermore, PAM can be instrumental in constructing process simulation models and evaluation of economic consistency of process models.

The third future direction is enterprise ontology development. Specifically, the AIS ontology development (Guan et al., 2013), the ODBRS ontology development (Gailly \& Geerts, 2013), the bunge-wand-weber (BWW) ontology development (Tegarden et al., 2013), and the supply chain ontology HVSC development (Geerts \& O'Leary, 2014). Although in ontology research, the integration of computer science and information systems into AIS ontology is an ongoing process with sustained and growing interests, little progress has been made so far (Guan et al., 2013). In the attempt to bridge that gap, the future directions may include empirically verifying REA ontology with its constructs, and mapping REA with other domain ontologies in the areas of social relations, constructivism, and AIS. Also, REA ontology research needs to explore new business areas such as auditing and assurance as they are currently influenced by information-communication technology.

The REA information system design theory appears to be sufficiently developed and has a solid potential to improve design, development, audit, and expansion of systems; however, it remains underutilized by the professionals and academics, possibly due to insufficient familiarity with its concepts and advantages. In this article, we attempted to address this lacuna by a structured and guided exposition of recent research that has developed the REA design theory.

\section{References}

Amrhein, D. G., Farewell, S., \& Pinsker, R. (2009) "REA and XBRL GL: Synergies for the 21st century business reporting system", International Journal of Digital Accounting Research, vol. 9, no.1: 127-152

Andersen, J., Elsborg, E., Henglein, F., Simonsen, J. G., \& Stefansen, C. (2006) "Compositional specification of commercial contracts", International Journal on Software Tools for Technology Transfer, vol. 8, no. 6: 485-516

Bakkenist, D., \& Bakkenist, T. (1999) "ExSpecT User Manual. Management \& ICT Consultants", available on-line at: http://www.exspect.com/ex641 usermanual.pdf.

Batra, D. (2012) "An event-oriented data modeling technique based on the cognitive semantics theory", Journal of Database Management, vol. 23, no. 4: $52-74$

Batra, D. \& Sin, T. (2008) "The READY Model: Patterns of dynamic behavior in REA-based accounting applications", Information Systems Management archive, vol. 25, no. 3: 200-210 
Bechini, A., Cimino, M. G. C. A., Marcelloni, F., \& Tomasi, A. (2008) "Patterns and technologies for enabling supply chain traceability through collaborative e-business", Information and Software Technology, vol. 50: 342-359

Card, D. N. \& Glass, R. L. (1990) Measuring Software Design Quality. Englewood Cliffs, NJ: Prentice Hall

Carnaghan, C. (2006) "Business process modeling approaches in the context of process level audit risk assessment: An analysis and comparison", International Journal of Accounting Information Systems, vol. 7: 170-204

Chen, J., D. \& O'Leary, M. D. (1995) "Domain-knowledge-guided schema evolution for accounting database systems", Expert Systems with Applications, vol. 9, no. 4: 491-501

Chen, P. P. (1976) "The entity-relationship model - toward a unified view of data", ACM Transactions on Database Systems, March: 9-36

Church, K. \& Smith, R. (2008) "REA ontology-based simulation models for enterprise strategic planning", Journal of Information Systems, vol. 22, no. 2: $301-329$

Church, K. S. \& Smith, R. E. (2007) "An extension of the REA framework to support balanced scorecard information requirements", Journal of Information Systems, vol. 21, no. 1:1-25

Denna, E. L., Jasperson, J., Fong, K., \& Middleman, D. (1994) "Modeling conversion process events", Journal of Information Systems vol. 8, no.1: 43-54

Dietz, J. L. G. (2006) Enterprise Ontology: Theory and Methodology. Berlin, Germany: Springer-Verlag

Dunn, C., Gerard, G., \& Grabski, S. V. (2016) "Resources-Events-Agents design theory: a revolutionary approach to enterprise system design", Communications of the Association for Information Systems, vol. 38, article 29

Dunn, C. (2001) "An investigation of localization as an element of cognitive fit in accounting model representations", Decision Sciences vol. 32, no.1: 55-94

Dunn, C. L. \& Grabski, S. V. (2000) "Perceived semantic expressiveness of accounting systems and task accuracy effects", International Journal of Accounting Information Systems, vol. 1, no. 2: 79-87

Dunn, C. L. \& McCarthy, W. E. (1997) "The REA accounting model: Intellectual heritage and prospects for progress", Journal of Information Systems, vol.11: $31-51$

Fabozzi, F. J., Drake, P. P., \& Polimeni, R. S. (2008) The Complete CFO Handbook. New York, NY: Wiley

Gailly, F. \& Geerts, G. L. (2013) "Ontology-driven business rule specification", Journal of Information Systems, vol. 27, no. 1: 79-104

Gailly, F., Laurier, W., \& Poels, G. (2008) "Positioning and formalizing the REA enterprise ontology", Journal of Information Systems, vol. 22, no. 2: 219-248 
Geerts, G. L. (2004) "An XML architecture for operational enterprise ontologies", Journal of Emerging Technologies in Accounting, vol. 1, no. 1: 73-90

Geerts, G. L. (2008) "Introduction to the REA 25th anniversary special section", Information Systems, vol. 22, no. 2: 215-217

Geerts, G. L. (2011) "A design science research methodology and its application to accounting information systems research", International Journal of Accounting Information Systems, vol. 12, no. 2: 142-151

Geerts, G. \& O'Leary, D. E. (2014) "A supply chain of things: the EAGLET ontology for highly visible supply chains", Decision Support Systems, vol. 63, no. $1: 3-22$

Geerts, G. L. \& Wang, H. J. (2007) "The timeless way of building REA enterprise systems", Journal of Emerging Technologies in Accounting, vol. 4, no. 1: 161-182

Geerts, G.L. McCarthy, W.E. (1997) "Modeling business enterprises as valueadded process hierarchies with resource-event-agent object templates", In: Sutherland J., Casanave C., Miller J., Patel P., Hollowell G. (eds) Business Object Design and Implementation, Springer, London

Geerts, G. L. \& McCarthy, W. E. (1999) "An accounting object infrastructure for knowledge- based enterprise models", IEEE Intelligent Systems and Their Applications, July/August: 89-94

Geerts, G. L. \& McCarthy, W. E. (2000) "Augmented intentional reasoning in knowledge- based accounting systems", Journal of Information Systems, vol. 14, no. 2: $127-150$

Geerts, G. L. \& McCarthy, W. E. (2002) "An ontological analysis of the economic primitives of the extended-REA enterprise information architecture", International Journal of Accounting Information Systems, vol. 3, no.1: 1-16

Geerts, G. L. \& McCarthy, W. E. (2004) "The ontological foundation of REA enterprise information systems", Working paper, Michigan State University. Available at http://citeseerx.ist.psu.edu/viewdoc/download?doi=10.1.1.91. 8191\&rep=rep1\&type $=$ pdf

Geerts, G. L. \& McCarthy, W. E. (2006) "Policy-level specifications in REA enterprise information systems", Journal of Information Systems, vol. 20, no. 2: $37-63$

Geerts, G. I., Graham, L. E., Mauldin, E. G., McCarthy, W. E., \& Richardson, V. J. (2013) "Integrating information technology into accounting research and practice", Accounting Horizons, vol. 27, no.4: 815-840

Geerts, G. L. \& McCarthy, W. E., \& Rockwell, S. R. (1996) "Automated integration of enterprise accounting models throughout the systems development life cycle", Intelligent Systems in Accounting, Finance and Management, vol. 5: 113-128

Gerard, G. J. (2005) "The REA pattern, knowledge structures, and conceptual modeling performance", Journal of Information Systems, vol. 19, no. 2: $57-77$ 
Grabski, S.V. \& Marsh, R.J. (1994) "Integrating accounting and manufacturing information systems: an $\mathrm{ABC}$ and REA-based approach", Journal of Information Systems, vol. 8, no. 2: 61-80

Gruber, T. R. (1993) "A translation approach to portable ontology specifications", Knowledge Acquisition, vol. 5, no. 2: 199-220

Grubic, T. \& Fan I. (2010) "Supply chain ontology: Review, analysis, and synthesis", Computers in Industry, vol. 61: 776-786

Gruninger, M. \& Lee, J. (2002) "Ontology applications and design: Introduction", Communications of the ACM, vol. 45, no.2: 39-41

Guan, J., Levitan, A. S., \& Kuhn, J. R. (2013) "How AIS can progress along with ontology research in IS", International journal of accounting information systems, vol. 14, no. 1: 21-38

Hruby P. (2006) Model-Driven Design of Software Applications with Business Patterns, Berlin, Germany: Springer Verlag

Huňka, F., Žáček, J., Meliš, Z., \& S Sevčík, J. (2011) "REA value chain and supply chain", Scientific Papers of the University of Pardubice, Series D, vol.16, no. 21: 68-77

Ito, S., \& Vymetal, D. (2013) "The formal REA model at the operational level", Applied Ontology, vol. 8: 275-300

Jones, S.P., \& Eber, J. M. (2003) How to write a financial contract: The Fun of Programming, Edited by J. Gibbons, and O. de Moor. Victoria, Australia: Palgrave Macmillan

Joseph, G., \& George, A. (2005) "Merging management accounting with database design", Management Accounting Quarterly, vol. 6, no. 2: 34-43

Kaplan, R. S., \& Norton, D.P. (1996) The Balanced Scorecard. Boston, MA: Harvard Business School Press

Kašík, J. (2011) "Business process modelling using REA ontology", Economics and Management, 16: 1047-1153

Laurier, W. \& Poels, G. (2012a) "Track and trace future, present, and past product and money flows with a resource-event-agent model", Information Systems Management, vol. 29, no. 2: 123-136

Laurier, W. \& Poels, G. (2012b) "Research note: ontology-based structuring of conceptual data modeling patterns", Journal of Database Management, vol. 23, no. 3: 50-64

Laurier, W. \& Poels, G. (2013) "Invariant conditions in value system simulation models", Decision Support Systems, vol. 56: 275-287

Leech, S. A. (1994) "Discussion of integrating accounting and manufacturing information systems: An ABC and REA-based approach", Journal of Information Systems, Fall: 81-83

Lupasc, A., Lupasc, I., \& Negoescu, G. (2010) "The role of ontologies for designing accounting information systems", Annals of Dunărea de Jos University. Fascicle I: Economics and Applied Informatics, vol. 16, no. 1: 101-108

Mayrhofer, D., \& Huemer, C. (2012) "Business-model-driven data engineering using the REA-DSL", Commerce and Enterprise Computing (CEC), IEEE 14th International Conference: 9-16 
McCarthy, W. E. (1982) "The REA accounting model: A generalized framework for accounting systems in a shared data environment", Accounting Review (July): 554-578

McCarthy, W. E. (2003) "The REA modeling approach to teaching accounting information systems", Issues in Accounting Education, vol. 18, no. 4: 427-441

Meliš, Z., Žáček, J., \& Huňka, F. (2013) "Comparison of MDA and DSM technologies for the REA ontology model creation", e-Informatica Software Engineering Journal, vol.7, no. 1: 7-14

Mora, M., Raisinghani, M., Gelman, O., \& Sicilia, M. A. (2011) Onto-ServSys: a service system ontology, The science of service systems. Service science: research and innovations (SSRI) series, Edited by H. Demirkan, J. Spohrer, and V. Krishna, Heidelberg, Germany: Springer

Morgan, G., \& Smircich, L. (1980) "The case for qualitative research", Academy of Management Review, vol. 5, no. 4: 491-500

Mui, C., \& McCarthy, W. E. (1987) "FSA: Applying AI techniques to the familiarization phase of financial decision making", IEEE Expert, vol. 2, no. 3: 33-41

O'Leary, D. E. (2004) "On the relationship between REA and SAP (ERP system databases)", International Journal of Accounting Information Systems, vol. 5, no. 1: $65-81$

O'Leary, D. E. (2010) "Enterprise ontologies: Review and an activity theory approach", International Journal of Accounting Information Systems, vol. 11, no. 4: 336-352

Peffers, K., Tuunanen, T., Rothenberger, M. A., \& Chatterjee, S. (2007) "A design science research methodology for information systems research", Journal of Management Information Systems, vol. 24, no. 3: 45-7

Poels, G., Maes, A., Gailly, F., \& Paemeleire, R. (2011) "The pragmatic quality of resources- events-agents diagrams: an experimental evaluation", Information Systems Journal, vol. 21, no. 1: 63-89

Rockwell, S. R., \& McCarthy W. E. (1999) "REACH: Automated database design integrating first-order theories, reconstructive expertise, and implementation heuristics for accounting information systems", Intelligent Systems in Accounting, Finance and Management, vol. 8, no. 3: 181-197

Sedbrook, T. A. (2010) "Maintaining enterprise knowledge with a REAEO driven semantic wiki", Journal of International Technology and Information Management, vol. 19, no. 1: 191

Sedbrook, T. A. (2012) "Modeling the REA enterprise ontology with a domain specific language", Journal of Emerging Technologies in Accounting, vol. 9, no. 1: 47-70

Sedbrook, T. \& Newmark, R. I. (2008) "Automating REA policy level specifications with semantic web technologies", Journal of Information Systems, vol. 22, no. 2: 249-277 
Sicilia, M. \& Mora, M. (2010) "On using the REA enterprise ontology as a foundation for service system representations", Lecture Notes in Business Information Processing, vol. 62: 135-147

Sonnenberg, C. \& Vom Brocke, J. (2014) "The missing link between bpm and accounting - using data for accounting in process-oriented organizations", Business Process Management Journal, vol. 20, no. 2: 213-246

Sutton, S. G. (2010) "A research discipline with no boundaries: Reflections on 20 years of defining AIS research", International Journal of Accounting Information Systems, vol. 11: 289-296

Sowa J. (1999) Knowledge Representation: Logical, Philosophical, and Computational Foundations. Pacific Grove, CA: Brooks/Cole Publishing.

$\mathrm{Su}, \mathrm{Y}$. (2009) "The analyze on accounting information system of third-party logistics enterprise", Canadian Center of Science and Education, vol. 1, no. 2: $124-127$

Tegarden, D. P., Schaupp, L. C., \& Dull, R. B. (2013) "Identifying ontological modifications to the Resource-Event-Agent (REA) enterprise ontology using a bunge-wand- weber ontological evaluation", Journal of Information Systems, vol. 27, no. 1: 105-128

Verdaasdonk, P. (2003) "An object-oriented model for ex ante accounting information", Journal of Information Systems, vol. 17, no. 1: 43-61

Veres, C. \& Mansson, G. (2005) "Cognition and modeling: foundations for research and practice", Journal of Information Technology Theory and Application, vol. 7, no.1

Vymětal, D, Hučka, M., Huňka, F., \& Kašík, J. (2008) "Production planning model using REA ontology", E+M Economics \& Management, vol. 4: 93-102

Weber, R. (1986) "Data models research in accounting: an evaluation of wholesale distribution software", Accounting Review, vol. 61, no. 3: 498-518

White, J. H. (2008) "REA modeling of mining companies", Journal of Information Systems, vol. 22, no. 2: 279-299

Weigand, H. \& Elsas, P. (2012a) "Construction and use of environmental management accounting systems with the REA business ontology", Journal of Emerging Technologies in Accounting, vol. 9, no. 1: 25-46

Weigand, H. \& Elsas, P. (2012b) "Model-based auditing using REA", International Journal of Accounting Information Systems, vol. 13, no. 3: 287-310

Zaharie, D., Pugna, I. B., Radulescu, C. (2011) "An ontology-based conceptual design of a data warehouse", Economic Computation \& Economic Cybernetics Studies \& Research, vol. 45, no. 2: 1-19 